\title{
Subsurface signatures and timing of extreme wave events along the southeast Indian coast
}

\author{
Rajesh R Nair ${ }^{1, *}$, Madhav K Murari ${ }^{2}$, C S Vijaya Lakshmi ${ }^{3}$, Ilya Buynevich ${ }^{4}$, \\ Ron J Goble ${ }^{5}$, P Srinivasan ${ }^{6}$, S G N Murthy ${ }^{6}$, Deshraj Trivedi ${ }^{3}$, Suresh \\ Chandra Kandpal $^{3}$, S M Hussain ${ }^{7}$, D Sengupta ${ }^{3}$ and Ashok K Singhvi ${ }^{2}$ \\ ${ }^{1}$ Department of Ocean Engineering, Indian Institute of Technology, Madras, India. \\ ${ }^{2}$ Physical Research Laboratory, Ahmedabad 380 009, India. \\ ${ }^{3}$ Department of Geology and Geophysics, Indian Institute of Technology Kharagpur, Kharagpur 721 302, India. \\ ${ }^{4}$ Department of Earth and Environmental Science, Temple University, \\ 1901 N., 13th Street, Philadelphia, PA 19122, USA. \\ ${ }^{5}$ Department of Geosciences, University of Nebraska, Lincoln, Nebraska 68588, USA. \\ ${ }^{6}$ Structural Engineering Research Centre, Chennai, India. \\ ${ }^{7}$ Madras University, Chennai, India. \\ *Corresponding author.e-mail: rajeshnair.iitkgp@gmail.com
}

\begin{abstract}
Written history's limitation becomes apparent when attempting to document the predecessors of extreme coastal events in the Indian Ocean, from 550-700 years in Thailand and 1000 years in Indonesia. Detailed ground-penetrating radar (GPR) surveys in Mahabalipuram, southeast India, complemented with sedimentological analyses, magnetic susceptibility measurements, and optical dating provide strong evidence of extreme wave events during the past 3700 years. The diagnostic event signatures include the extent and elevation of the deposits, as well as morphologic similarity of buried erosional scarps to those reported in northern Sumatra region. Optical ages immediately overlying the imaged discontinuities that coincides with high concentration of heavy minerals date the erosional events to $340 \pm 35,350 \pm 20,490 \pm 30$, $880 \pm 40,1080 \pm 60,1175 \pm 188,2193 \pm 266,2235 \pm 881,2489 \pm 293,2450 \pm 130,2585 \pm 609,3710 \pm$ 200 years ago. These evidences are crucial in reconstructing paleo extreme wave events and will pave the way for regional correlation of erosional horizons along the northern margin of Indian Ocean.
\end{abstract}

\section{Introduction}

The 26 December 2004 tsunami affected numerous countries along the Indian Ocean, with immediate and profound societal consequences. This event further emphasized the need for understanding the processes leading to extreme wave events and their recurrence intervals, along with an assessment of their impact on coastal landscapes and ecosystems.
Historical archives of the origin, timing, and impact of tsunamis, storms, and floods along the margins of the Indian Ocean are often of limited value and scientists must rely on geological signatures to reconstruct the extent and timing of substantial erosional events. Monecke et al (2008) documented a 1000-year sedimentary record of tsunami recurrence in northern Sumatra and suggested that large tsunamis in Ache recur with an interval of

Keywords. Extreme events; ground-penetrating radar; heavy minerals; magnetic susceptibility; optical luminescence dating. 
500-700 years. In the Mahabalipuram archeological site, $55 \mathrm{~km}$ south of Chennai (Madras), Rajendran et al (2006) reported evidence of two probable extreme wave events at 1000 and 1500 years ago. Study of foraminiferal assemblages and spatial distribution in tsunami inundation areas along Nagappattinam coast by Nagendra et al (2005) indicated that the sediments were delivered by tsunami waves from shallow neritic zone along the coast. Similar evidence of shoreproximal sediment source for the 2004 extreme wave event has also been provided by the analysis of the distribution of paleodose values in opticallystimulated luminescence (OSL) dates of coastal deposits (Murari et al 2007).

High-resolution GPR studies (by the IIT Madras group) of erosional signatures from the beach ridge system in Mahabalipuram were carried out to assess the extent and geometry of erosional disconformities (buried scarps; Buynevich et al 2007a) and to compare with the existing record of past extreme oceanographic events. A recent paper by Vijayalakshmi et al (2010) describes these transects, along with a detailed treatment of textural and mineralogical characteristics. This paper presents evidence for extreme wave events based on additional high-resolution geophysical images from adjacent sites, complemented with a new set of optical dates of subsurface event horizons.

The recent paper (Vijayalakshmi et al 2010), demonstrates the rich geological characteristics in the same area (granularity, texture and magnetic susceptibility variations) that is suggestive of the possibility of extreme wave events and is thus presently studied further to estimate whether high resolution subsurface signatures and timing of these deposits can be correlatable with reported diagnostic features in the same area reported by Vijayalakshmi et al (2010). Our study will test the interpretations of Vijayalakshmi et al (2010), who attributed textural and mineralogical properties of landward-fining sequences along this coastal region to extreme wave events.

\section{Data and methods}

The beach ridge system in Mahabalipuram is situated on the east coast of India (figure 1). Palar River meets the sea south of Mahabalipuram near Madras. Buckingham canal, a backwater body is located about $1.5 \mathrm{~km}$ west of Mahabalipuram, with outlets at Covelong and Kalpakkam. The shoreline is oriented $\mathrm{N}-\mathrm{S}$ and the beaches have extensive subaerial and subaqueous sand volumes (Subrahmanyan and Selvan 2001). Inner shelf in this region (Murthy et al 1995) is covered with sandy sediments (Selvaraj and Ram Mohan 2003) and acts as an offshore sediment source during extreme wave events. Rajendran et al (2006) reported that considering an average erosion of $55 \mathrm{~cm} / \mathrm{yr}$, the shoreline might be $800 \mathrm{~m}$ seaward of the present coast 1500 years ago (Ramaiyan et al 1997). The run-up height and inundation limit of the study region is $4.3 \mathrm{~m}$ and $650 \mathrm{~m}$, respectively (Srinivasulu et al 2007).

In prograded sandy sequences, most paleo-storm/ tsunami signatures occur within the upper few meters and trenches often offer more information than point-source cores. To get below the water table, other techniques may be needed, but GPR provides the most viable technique for imaging both unsaturated and saturated portions of the sequence, as long as there is no saltwater or thick clays (Meyers et al 1996; Buynevich et al 2007b).

\subsection{Subsurface imaging and sedimentological analysis}

High-resolution GPR surveys using a digital Geophysical Survey Systems Incorporated (GSSI) SIR-20 system with a $400 \mathrm{MHz}$ antenna provided continuous high-resolution image across the prograded coastal sequence (figure 1). This technique allows rapid determination of depth, spatial extent, and the geometry of subsurface features and bounding surfaces, including erosional unconformities (Jol et al 1996; Buynevich et al 2007a, 2009). GPR data were post-processed with RADAN 6.0 software. Radargram processing included spatial filtering and topographic corrections (surface normalization). The data is then subjected to time migration for all the four transects that effectively resolved the reflecting discontinuities spatially. This procedure, thus removed several other very weak dipping reflectors that was originally masking the actual discontinuities to some extent. Topographic profiles were collected using a total station survey system and low-field magnetic susceptibility of sediments was measured with a Bartington MS2 system. The total line of GPR data acquired, processed, interpreted and presented in this paper for profiles S1, R1, R2 and R3 are shown as green boxes in figure 2. Contrasting electromagnetic properties of heavy-mineral concentrations (HMCs) typically formed by high-energy events (Babu et al 2007; Buynevich et al 2007a) and background quartz-rich sediments aided the identification of erosional features in the subsurface records. Whereas morphological and sedimentological characteristics of the 2004 tsunami have been documented (Jankaew et al 2008; Monecke et al 2008) and are used as modern analogues, at present there is no comparable subsurface evidence of a known 


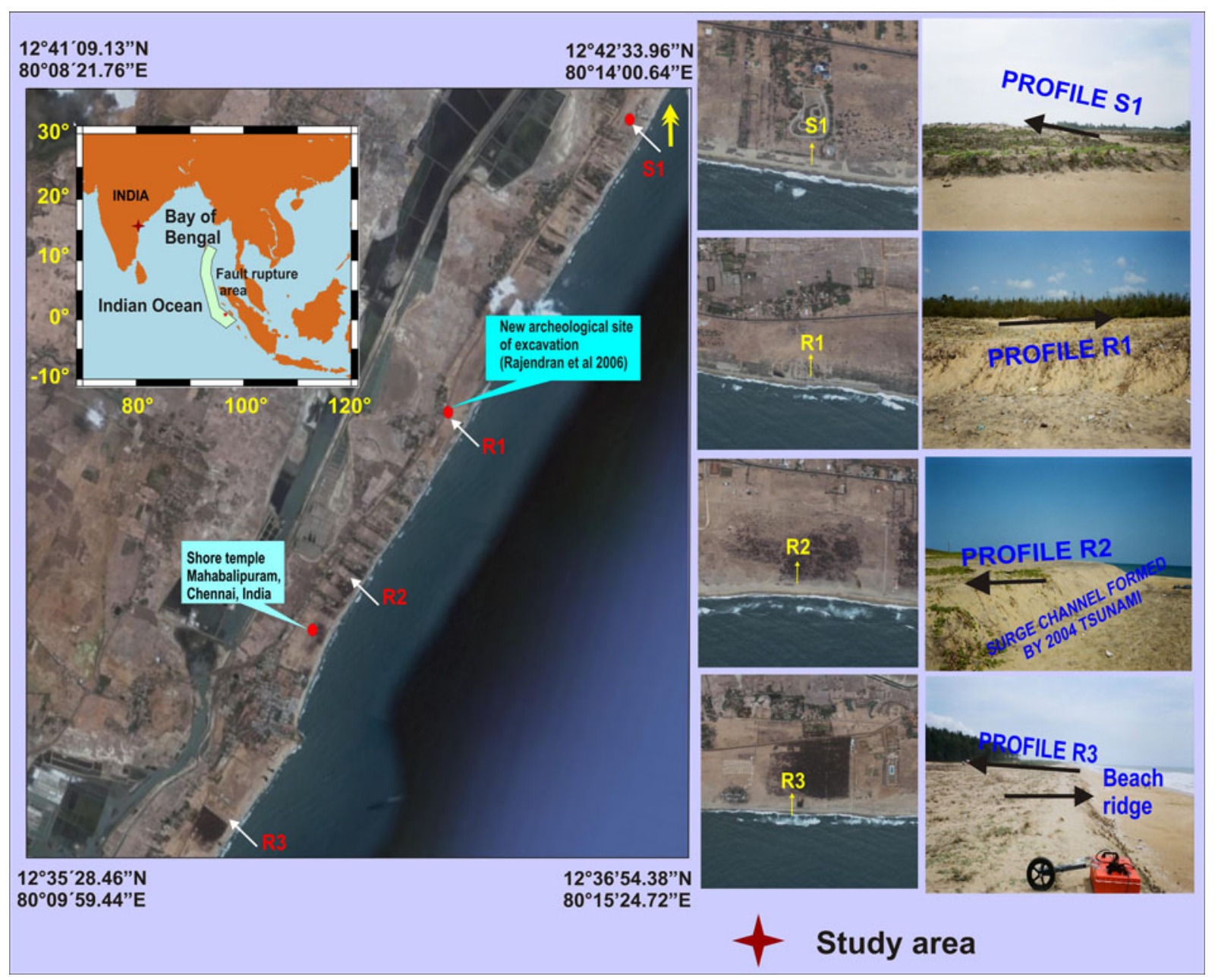

Figure 1. Location of the study area along the east coast of India, with widely spaced transects along with the corresponding photographs of the field area. Top inset shows the index map of the study area indicating the 2004 earthquake fault rupture to the epicenter with respect to the study area (source: Google earth 2009). R1 and R2 in this paper corresponds to profiles named as P1 and P2 based on science news feature published in Eos (Nair et al 2010).

tsunami event to compare to the buried erosional features described in this study.

Granulometric measurements using Malvern Mastersizer 2000 particle size analyzer indicated that sediments were moderately to well sorted and beds are normally graded overall; however some horizons exhibit multiple cycles of normal grading. The analysis was carried out for samples of size $<10 \mu \mathrm{m}$ and then treated with $\mathrm{H}_{2} \mathrm{O}_{2}$, thus leaving out clay particles and subsequently drying in oven. The measurement procedure includes creating a measurement file, adding background readings of the dispersant and taking three sets of readings and flushing of the stirring and pumping mechanism before obtaining the background of the next sample.

Mean grain size in the medium-fine sand range $(<1.5 \varphi)$ with volume percentage of $8-10 \%$ implied sediment transport in suspension, rather than by traction. Morton et al (2007) suggest that such a transport under suspension occurs during extreme wave event, with flow depth $>10 \mathrm{~m}$. This depth facilitates sediment transport in suspension, and distribution of sediment load over a larger region during initiation and deceleration of the flow and the sediments are deposited under gravity. The spatial extent of these deposits was $>13 \mathrm{~km}$ parallel to shore, and was confirmed with the GPR surveys as shown in figure 1 with locations marked by white arrows. Figure 1 represents all the four GPR transects through the beach ridges that were examined to define the spatial extent of key subsurface signatures. These profiles confirmed the alongshore continuity of signatures. Table 1 represents the distance versus phi scale measurement of grain size showing the landward fining of grains confirming the control of granularity due to an extreme wave event.

As for magnetic (MS) measurements, we sample individual layers (small samples of 1-2 $\mathrm{cm}^{3}$ ) and measure in the lab using Bartington Magnetic 


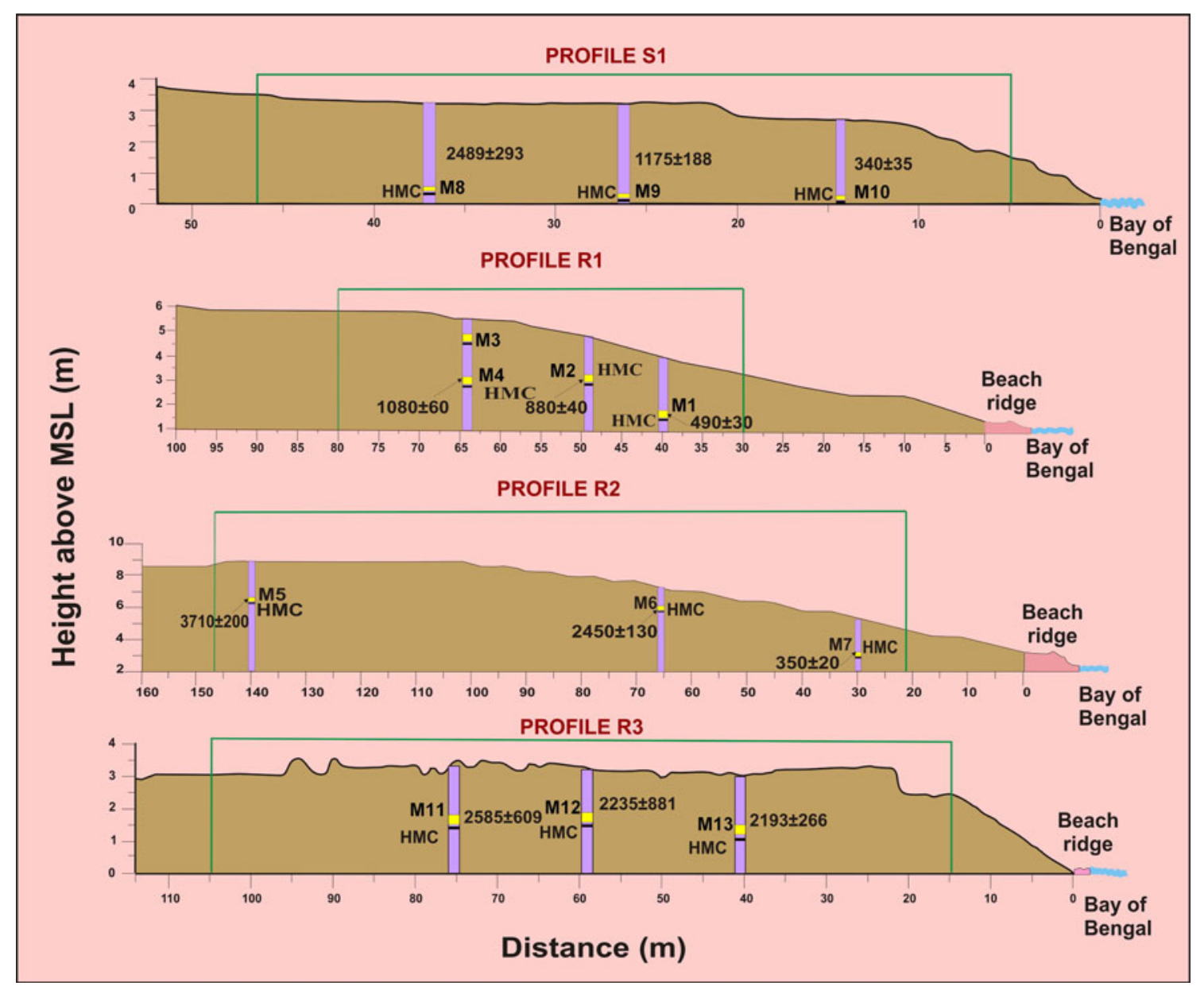

Figure 2. Topographic profiles of shore-normal transect S1 (location shown in figure 1; HMC - heavy mineral concentration) along with their OSL ages of deposits immediately overlying heavy minerals. Segments of the trenches highlight presence of HMCs in the upper part of the coastal plain. MSL - mean sea level. Green boxes represent the extend of GPR transects shown in figure 3.

Susceptibility meter. Sometimes, the heavymineral layers are too thin to sample. This way, one can only do it directly in the field. Most of our samples are thick enough so we measured in the lab. In the manual trenches with exposure of heavy-mineral or other even layers, we pressed a U-channel (half of a plastic core) into the trench, wrap it with tape and made $20-30 \mathrm{~cm}$ long sections and measured MS every $2-3 \mathrm{~cm}$.

\subsection{Optical dating}

Optically-stimulated luminescence (OSL) dating of quartz mineral separates from sediments provided depositional ages of three buried scarps (posterosional deposits) (corresponding to M1-M13; figure 2). Luminescence dating has been applied successfully on coastal deposits (Clarke et al 2002; Sommerville et al 2003; Murari et al 2007).

The luminescence dating applications for the dating of sediments is well-established (Aitken 1998; Singhvi and Porat 2008). The method uses quartz separated from the sediments to estimate total radiation exposure seen since its deposition. This is estimated via optically stimulated luminescence. The radiation exposure arises from environmental radioactivity. The environmental dose rate (in $\mathrm{Gy} / \mathrm{ka}$ ) is because of the decay of $U$, $\mathrm{Th}$ and $\mathrm{K}$ in ambient stratum and is computed via their elemental concentration. In the present case, the likely adverse effect of heavy minerals on the dose-rate determination was minimized during sampling. Thus, the samples were taken from the depth interval $15-20 \mathrm{~cm}$ above the erosional surfaces and HMC horizons.

The optical dating analysis followed the Single Aliquot Regeneration (SAR) measurement protocol (Wintle and Murray 2006; Wintle 2008), that additionally accounted for sensitivity changes during the measurement of natural OSL. As an additional improvement, we used component specific luminescence analysis (Murari and Singhvi 2006; Murari 2008).

Luminescence dating of sediments provides the age of the most recent burial event. The method 
relies on the premise that daylight exposure during the transport and burial, photobleaches the geological luminescence to near zero residual level. After burial, the daylight exposure ceases and a reaccumulation of luminescence occurs due to radiation arising from the decay ambient radioactivity, viz., $\mathrm{U}$, Th and K. As a first approximation, the radiation exposure is constant over the time scales of interest. Consequently, the luminescence buildup in the mineral is proportional to the burial time. The burial age of the sample is thus a ratio of acquired luminescence and the rate of luminescence acquisition (i.e., the radiation dose rate, Aitken 1998; Murray and Olley 2002; Singhvi and Porat 2008). Recent work on 2004 Tsunami sediments suggested that the sediment transported to land, was principally derived from the upper sediment layers of the coastal shelf region. Its geological luminescence was reset during the residence of mineral in the region, due to multiple reworking and onsite sun exposure under water (Murari et al 2007).

For the dating analysis, the samples were pretreated with $10 \% \mathrm{HCl}$ to remove carbonate and $\mathrm{H}_{2} \mathrm{O}_{2}$ to remove the organic matter. This was followed by sieving of $90-150 \mu \mathrm{m}$ grain size fraction. Examination of sample by microscope indicated the presence of dark minerals. Therefore a low field control (LFC Model-2) Frantz isodynamic magnetic separator was used to remove magnetic and nonmagnetic mineral assemblages from the sample. Forward and side slopes were set at $100^{\circ}$ and $15^{\circ}$, respectively. In order to separate the quartz from heavy minerals, variable magnetic field was used by varying current from $1-1.25 \mathrm{~mA}$. The resulting samples were free from magnetic minerals. A heavy liquid sodium polytungstate $\left(\rho 2.58 \mathrm{~g} / \mathrm{cm}^{3}\right)$ was further used to separate quartz from feldspar and other low density minerals, and HF etching for 80 minutes by $40 \% \mathrm{HF}$, thus removing the outer alpha irradiated skin and dissolved residual feldspars. The purity of the extracted quartz in respect of feldspar contamination was checked using IRSL for $100 \mathrm{~s}$ at room temperature (Jain and Singhvi 2001).

An automated Risoe TL/OSL reader (TL-DA15) was used to read the OSL signal. The stimulation was using blue LEDs stimulating at $470 \mathrm{~nm}$ and the detection optics comprised Hoya U-340 and Schott BG-39 colour glass filters coupled to an EMI 9235 QA photomultiplier tube and irradiations were made using a $40 \mathrm{mCi}{ }^{90} \mathrm{Sr} /{ }^{90} \mathrm{Y}$ beta source (Bøtter-Jensen et al 2003). The paleodose estimates were made using both the conventional Single Aliquot Regeneration (SAR) and its improved version of natural sensitivity corrected SAR protocols (Singhvi et al 2008). Further refinements were the estimation of paleodose after extraction of the amplitude of the fast component in the
OSL decay of quartz (Murari 2008). These enabled robustness of the dating analysis.

Elemental concentration of $\mathrm{U}^{238}$ and $\mathrm{Th}^{232}$ were determined using thick source alpha counting technique. The sample is powdered to less than $2 \mu \mathrm{m}$ size and then spread on a $42 \mathrm{~mm}$ diameter $\mathrm{ZnS}(\mathrm{Ag})$ scintillation screen, positioned in a sealed perspex holder. K concentration was measured using thallium activated sodium iodide (NaI) gamma ray scintillation spectrometer. OSl sensitivity of the samples was high such that the signal-to-noise ratio even for such young samples was over 30 . The dose recovery test (Wintle and Murray 2006) provided doses within $4 \%$ of the given dose. Most aliquots gave a recycling ratio of $0.90-1.10$.

\subsubsection{Paleodose estimation (NCF-SAR)}

In conventional SAR measurement protocol, sensitivity changes are corrected for every regeneration doses by normalizing them with subsequent test doses. Singhvi et al (2008) suggested that the change in sensitivity during the natural OSL measurement itself is not accounted by the SAR protocol. Thus, for many samples, saturation was seen in the regeneration curve, whilst the natural signal intensity was significantly higher than the saturation limit. To correct such a sensitivity change during the readout of natural OSL, the intensity of $110^{\circ} \mathrm{C}$ TL peak following a small test dose was measured both before (TL1) and after (TL2) measurement of natural signal. Any change in sensitivity, i.e., the ratio of $110^{\circ} \mathrm{C}$ TL peaks (TL1/TL2) deviates from unity and can be used to correct for the same.

\subsubsection{Component specific dose SAR (CSD-SAR)}

The nature of OSL decay suggests that the time dependence of OSL emission can be expressed by sum of exponentials. Typically three exponential terms can adequately describe the decay of OSL from quartz and the three exponentials are referred to as fast, medium and slow components depending on their lifetime under a given stimulation (Bailey et al 1997; Jain et al 2003; Murari 2008). The bleachability of different components implies that only the fast components are to be used for partially or heterogeneously bleached sample. The fast component has highest probability of being bleached under such conditions and hence will most likely provide reliable results. Thus the ages were computed after mathematically extracting the fast component from each of the natural, regenerated and test dose decay curves and then using these for analysis. 
Table 1. Grain size (phi units) versus distance from the shore ( $m$ ) for the all the four transects $S 1, R 1, R 2$ and $R 3$ from the corresponding trenches as shown in figure 4 .

\begin{tabular}{|c|c|c|c|c|c|c|c|c|c|c|c|}
\hline \multicolumn{6}{|c|}{ Profile S1 } & \multicolumn{6}{|c|}{ Profile R1 } \\
\hline \multicolumn{2}{|c|}{ Sample a } & \multicolumn{2}{|c|}{ Sample b } & \multicolumn{2}{|c|}{ Sample c } & \multicolumn{2}{|c|}{ Sample a } & \multicolumn{2}{|c|}{ Sample b } & \multicolumn{2}{|c|}{ Sample c } \\
\hline $\begin{array}{l}\text { Grain } \\
\text { size }\end{array}$ & $\begin{array}{l}\text { Dist. } \\
\text { from } \\
\text { shore }\end{array}$ & $\begin{array}{c}\text { Grain } \\
\text { size }\end{array}$ & $\begin{array}{l}\text { Dist. } \\
\text { from } \\
\text { shore }\end{array}$ & $\begin{array}{c}\text { Grain } \\
\text { size }\end{array}$ & $\begin{array}{l}\text { Dist. } \\
\text { from } \\
\text { shore }\end{array}$ & $\begin{array}{c}\text { Grain } \\
\text { size }\end{array}$ & $\begin{array}{l}\text { Dist. } \\
\text { from } \\
\text { shore }\end{array}$ & $\begin{array}{c}\text { Grain } \\
\text { size }\end{array}$ & $\begin{array}{l}\text { Dist. } \\
\text { from } \\
\text { shore }\end{array}$ & $\begin{array}{c}\text { Grain } \\
\text { size }\end{array}$ & $\begin{array}{l}\text { Dist. } \\
\text { from } \\
\text { shore }\end{array}$ \\
\hline 0.59 & 34.02 & 0.07 & 22.23 & 0.15 & 14.31 & 0.00 & 63.59 & 0.00 & 46.50 & 0.00 & 39.96 \\
\hline 0.64 & 37.09 & 0.07 & 26.06 & 0.15 & 16.61 & 0.17 & 65.10 & 0.00 & 48.01 & 0.00 & 41.97 \\
\hline 0.73 & 40.15 & 0.24 & 28.87 & 0.20 & 19.42 & 0.34 & 67.61 & 0.00 & 49.52 & 0.00 & 44.49 \\
\hline 0.86 & 42.97 & 0.37 & 31.93 & 0.37 & 21.97 & 0.51 & 69.87 & 0.00 & 51.27 & 0.00 & 47.00 \\
\hline 1.03 & 46.03 & 0.55 & 35.26 & 0.55 & 24.53 & 0.60 & 72.39 & 0.12 & 53.29 & 0.04 & 49.26 \\
\hline 1.30 & 49.10 & 0.68 & 38.32 & 0.68 & 25.80 & 0.78 & 75.15 & 0.25 & 54.79 & 0.17 & 50.52 \\
\hline 1.60 & 51.41 & 0.86 & 41.39 & 1.03 & 26.82 & 0.86 & 77.41 & 0.51 & 56.55 & 0.25 & 51.02 \\
\hline 1.87 & 49.11 & 1.12 & 43.94 & 1.38 & 25.04 & 0.99 & 79.43 & 0.69 & 57.31 & 0.51 & 49.26 \\
\hline 2.04 & 46.05 & 1.43 & 41.39 & 1.60 & 22.48 & 1.21 & 81.44 & 0.99 & 55.80 & 0.65 & 47.50 \\
\hline 2.22 & 42.99 & 1.52 & 38.83 & 1.69 & 20.69 & 1.43 & 83.20 & 1.17 & 53.79 & 0.78 & 44.99 \\
\hline 2.31 & 40.18 & 1.65 & 35.77 & 1.82 & 18.14 & 1.73 & 81.44 & 1.25 & 52.03 & 0.86 & 42.23 \\
\hline 2.44 & 37.11 & 1.78 & 33.21 & 2.04 & 15.07 & 1.99 & 78.42 & 1.34 & 50.02 & 0.99 & 39.96 \\
\hline 2.57 & 34.05 & 1.87 & 30.15 & 2.13 & 12.52 & 2.16 & 75.40 & 1.43 & 48.76 & 1.04 & 36.95 \\
\hline 2.75 & 30.99 & 1.96 & 27.34 & 2.31 & 9.96 & 2.34 & 72.89 & 1.51 & 46.75 & 1.17 & 34.18 \\
\hline 2.97 & 27.93 & 2.09 & 24.27 & 2.48 & 6.90 & 2.55 & 69.87 & 1.60 & 44.99 & 1.25 & 31.17 \\
\hline 3.76 & 26.66 & 2.26 & 20.69 & 2.66 & 5.11 & 2.94 & 65.60 & 1.82 & 41.72 & 1.38 & 28.40 \\
\hline 4.42 & 26.67 & 2.48 & 17.88 & 2.84 & 4.34 & 3.20 & 64.09 & 2.03 & 39.46 & 1.82 & 25.39 \\
\hline 5.08 & 26.68 & 2.92 & 17.12 & 3.41 & 3.83 & 3.81 & 63.84 & 2.21 & 37.45 & 2.12 & 25.13 \\
\hline 5.78 & 26.69 & 3.45 & 17.12 & 3.89 & 3.83 & 4.24 & 63.84 & 2.42 & 36.45 & 2.60 & 25.13 \\
\hline 6.44 & 26.70 & 3.93 & 17.12 & 5.21 & 3.83 & 4.76 & 63.84 & 2.90 & 36.45 & 3.12 & 25.13 \\
\hline 7.10 & 26.71 & 4.29 & 17.12 & 5.82 & 3.83 & 5.20 & 63.84 & 3.38 & 36.45 & 3.59 & 25.13 \\
\hline 7.67 & 26.72 & 4.59 & 17.12 & 6.48 & 3.83 & 5.76 & 63.84 & 3.77 & 36.45 & 4.03 & 25.13 \\
\hline 8.29 & 26.73 & 4.99 & 17.12 & 7.05 & 3.83 & 6.72 & 63.84 & 4.55 & 36.45 & 4.59 & 25.13 \\
\hline 8.77 & 26.74 & 5.34 & 17.12 & 7.85 & 3.83 & 7.45 & 63.84 & 5.28 & 36.45 & 5.28 & 25.13 \\
\hline 9.30 & 26.75 & 5.78 & 17.12 & 8.59 & 3.83 & 8.49 & 63.84 & 6.54 & 36.45 & 6.37 & 25.13 \\
\hline 10.00 & 26.76 & 6.35 & 17.12 & 9.30 & 3.83 & 10.10 & 63.84 & 7.41 & 36.45 & 7.45 & 25.13 \\
\hline 10.75 & 26.77 & 6.88 & 17.12 & 10.13 & 3.83 & 10.53 & 63.84 & 8.54 & 36.45 & 8.54 & 25.13 \\
\hline 11.36 & 26.78 & 7.32 & 17.12 & 10.57 & 3.83 & 10.96 & 63.84 & 9.32 & 36.45 & 9.36 & 25.13 \\
\hline 11.85 & 26.79 & 8.24 & 17.12 & 11.05 & 3.83 & 11.62 & 63.84 & 9.97 & 36.45 & 10.36 & 25.13 \\
\hline 12.02 & 26.79 & 10.44 & 17.12 & 11.63 & 3.83 & 11.83 & 63.84 & 11.44 & 36.45 & 11.27 & 25.13 \\
\hline
\end{tabular}

\section{Results and discussions}

Shore-normal GPR surveys reveal a series of distinct, steep (6-19: M1-M13 excluding M3) seaward-dipping buried disconformities (figures 2 and 3). M3 is another quartz sample taken just above M4 to confirm the fining upward sequences obtained from granularity measurements. Based on trench exposures (figure 4) and sediment cores along geophysical transects, each strong reflection coincides with heavy-mineral concentrations (HMCs). Volume magnetic susceptibility measurements of the HMCs for M1-M13 excluding M3, yield high values of $382.6,611.4,91.3,102,530$, $312.1,269.2,257.7,464.5,851,942.9,489$ and 604.2 $\left(\times 10^{-5}\right.$ SI units $)$ compared to the background magnetic susceptibility of $5-10 \times 10^{-5}$ SI units for quartz-rich sands. These values likely reflect the intensity of reworking processes and removal of lighter minerals by waves and currents. Transect S1 demarcates the lateral extent of buried scarps (post-erosional deposits) (M8 $\sim 30 \mathrm{~m}, \mathrm{M} 9 \sim 20 \mathrm{~m}$, M10 $10 \mathrm{~m}$ ) as shown in figure 3 with prominent dipping reflectors (slopes $13.1^{\circ}-14.5^{\circ}$ ). Similarly lateral extend of buried scarps (transect R1: M3 $\sim 65 \mathrm{~m}, \mathrm{M} 2 \sim 45 \mathrm{~m}, \mathrm{M} 1 \sim 35 \mathrm{~m}$; transect R2 : M5 $\sim 140 \mathrm{~m}, \mathrm{M} 6 \sim 70 \mathrm{~m}, \mathrm{M} 7 \sim 30 \mathrm{~m}$; transect R3: M11 $\sim 75 \mathrm{~m}, \mathrm{M} 12 \sim 60 \mathrm{~m}, \mathrm{M} 13 \sim 40 \mathrm{~m}$ ) for the other three profiles as shown in figure 3 . The slopes of these erosional scarp varies from $6^{\circ}-19^{\circ}$ as shown in figure 3. In northern Sumatra region, Monecke et al (2008) recorded erosional scarps at a depth 


\begin{tabular}{|c|c|c|c|c|c|c|c|c|c|c|c|}
\hline \multicolumn{6}{|c|}{ Profile R2 } & \multicolumn{6}{|c|}{ Profile R3 } \\
\hline \multicolumn{2}{|c|}{ Sample a } & \multicolumn{2}{|c|}{ Sample b } & \multicolumn{2}{|c|}{ Sample c } & \multicolumn{2}{|c|}{ Sample a } & \multicolumn{2}{|c|}{ Sample b } & \multicolumn{2}{|c|}{ Sample c } \\
\hline $\begin{array}{l}\text { Grain } \\
\text { size }\end{array}$ & $\begin{array}{l}\text { Dist. } \\
\text { from } \\
\text { shore }\end{array}$ & $\begin{array}{c}\text { Grain } \\
\text { size }\end{array}$ & $\begin{array}{l}\text { Dist. } \\
\text { from } \\
\text { shore }\end{array}$ & $\begin{array}{c}\text { Grain } \\
\text { size }\end{array}$ & $\begin{array}{l}\text { Dist. } \\
\text { from } \\
\text { shore }\end{array}$ & $\begin{array}{c}\text { Grain } \\
\text { size }\end{array}$ & $\begin{array}{l}\text { Dist. } \\
\text { from } \\
\text { shore }\end{array}$ & $\begin{array}{c}\text { Grain } \\
\text { size }\end{array}$ & $\begin{array}{l}\text { Dist. } \\
\text { from } \\
\text { shore }\end{array}$ & $\begin{array}{c}\text { Grain } \\
\text { size }\end{array}$ & $\begin{array}{l}\text { Dist. } \\
\text { from } \\
\text { shore }\end{array}$ \\
\hline 0.15 & 140.00 & 0.00 & 65.75 & 0.00 & 21.00 & 0.33 & 37.00 & 0.24 & 25.75 & 0.11 & 14.75 \\
\hline 0.24 & 142.50 & 0.00 & 67.75 & 0.00 & 23.50 & 0.42 & 39.00 & 0.24 & 28.25 & 0.11 & 18.00 \\
\hline 0.37 & 144.00 & 0.11 & 70.75 & 0.00 & 26.00 & 0.54 & 41.50 & 0.24 & 30.25 & 0.16 & 20.00 \\
\hline 0.49 & 146.50 & 0.24 & 73.00 & 0.11 & 28.75 & 0.72 & 44.00 & 0.29 & 32.50 & 0.24 & 22.75 \\
\hline 0.62 & 148.75 & 0.41 & 76.00 & 0.24 & 31.25 & 0.98 & 48.50 & 0.37 & 35.00 & 0.37 & 24.25 \\
\hline 0.80 & 151.25 & 0.58 & 79.75 & 0.49 & 34.00 & 1.15 & 51.25 & 0.50 & 37.75 & 0.59 & 24.75 \\
\hline 0.97 & 154.00 & 0.84 & 83.00 & 0.84 & 35.50 & 1.41 & 53.50 & 0.63 & 39.00 & 0.89 & 23.25 \\
\hline 1.18 & 156.00 & 1.10 & 84.50 & 1.31 & 34.00 & 1.62 & 52.50 & 0.76 & 39.50 & 1.02 & 21.00 \\
\hline 1.44 & 156.75 & 1.40 & 82.75 & 1.48 & 31.50 & 1.75 & 51.00 & 1.02 & 37.75 & 1.15 & 18.75 \\
\hline 1.61 & 156.00 & 1.70 & 78.25 & 1.61 & 28.75 & 1.92 & 47.75 & 1.11 & 36.50 & 1.32 & 15.25 \\
\hline 1.78 & 154.50 & 1.91 & 74.25 & 1.83 & 25.75 & 2.05 & 45.00 & 1.23 & 33.75 & 1.45 & 13.00 \\
\hline 1.91 & 153.25 & 2.04 & 70.50 & 2.00 & 22.25 & 2.14 & 42.25 & 1.36 & 30.25 & 1.58 & 9.50 \\
\hline 2.00 & 151.50 & 2.22 & 66.75 & 2.22 & 18.25 & 2.27 & 38.25 & 1.49 & 25.75 & 1.80 & 5.50 \\
\hline 2.13 & 149.00 & 2.43 & 63.00 & 2.60 & 13.75 & 2.49 & 34.25 & 1.62 & 20.25 & 1.97 & 3.00 \\
\hline 2.30 & 146.50 & 2.60 & 60.50 & 3.03 & 12.25 & 2.70 & 31.00 & 1.88 & 15.00 & 2.18 & 1.50 \\
\hline 2.43 & 143.75 & 2.99 & 58.00 & 3.76 & 12.25 & 2.87 & 30.00 & 2.05 & 12.75 & 2.49 & 1.25 \\
\hline 2.65 & 140.75 & 3.46 & 58.00 & 4.37 & 12.25 & 3.22 & 29.50 & 3.00 & 12.75 & 3.18 & 1.25 \\
\hline 3.08 & 136.25 & 4.15 & 58.00 & 5.01 & 12.25 & 3.61 & 29.50 & 3.61 & 12.75 & 3.65 & 1.25 \\
\hline 3.55 & 133.25 & 4.84 & 58.00 & 5.53 & 12.25 & 4.56 & 29.50 & 4.30 & 12.75 & 3.99 & 1.25 \\
\hline 4.06 & 132.75 & 5.61 & 58.00 & 6.13 & 12.25 & 5.12 & 29.50 & 5.16 & 12.75 & 4.34 & 1.25 \\
\hline 4.67 & 132.75 & 6.86 & 58.00 & 6.65 & 12.25 & 5.59 & 29.50 & 5.81 & 12.75 & 4.68 & 1.25 \\
\hline 5.61 & 132.75 & 7.38 & 58.00 & 7.20 & 12.25 & 6.24 & 29.50 & 6.54 & 12.75 & 5.16 & 1.25 \\
\hline 6.34 & 132.75 & 9.01 & 58.00 & 7.76 & 12.25 & 6.80 & 29.50 & 7.10 & 12.75 & 5.59 & 1.25 \\
\hline 7.85 & 132.75 & 9.78 & 58.00 & 8.37 & 12.25 & 7.40 & 29.50 & 7.88 & 12.75 & 6.32 & 1.25 \\
\hline 9.01 & 132.75 & 10.73 & 58.00 & 8.92 & 12.25 & 7.92 & 29.50 & 8.57 & 12.75 & 7.10 & 1.25 \\
\hline 10.34 & 132.75 & 11.33 & 58.00 & 9.96 & 12.25 & 8.74 & 29.50 & 9.13 & 12.75 & 7.53 & 1.25 \\
\hline 11.63 & 132.75 & 11.98 & 58.00 & 10.86 & 12.25 & 9.51 & 29.50 & 9.77 & 12.75 & 8.13 & 1.25 \\
\hline 12.15 & 132.75 & 12.45 & 58.00 & 11.29 & 12.25 & 10.38 & 29.50 & 10.16 & 12.75 & 8.70 & 1.25 \\
\hline 12.49 & 132.75 & 12.92 & 58.00 & 11.76 & 12.25 & 11.07 & 29.50 & 10.59 & 12.75 & 9.34 & 1.25 \\
\hline 12.88 & 132.75 & 13.44 & 58.00 & 12.28 & 12.25 & 11.67 & 29.50 & 10.98 & 12.75 & 9.90 & 1.25 \\
\hline
\end{tabular}

of around 2-3 $\mathrm{m}$ from the surface, and Jankaew et al (2008) reported sediments from two swales $\mathrm{X}$ and $\mathrm{Y}$ separated by $500 \mathrm{~m}$ at a depth within $1 \mathrm{~m}$. Babu et al (2007) recently obtained high magnetite percentage in southwest coast of India, and interpreted it as due to intensity of reworking processes associated with 2004 extreme wave event. Sedimentological analysis revealed fining-upward sequences within the trench as well as a landwardfining sequence. The spatial extent of at least $13 \mathrm{~km}$ along the coast (including Mahabalipuram and adjoining areas as shown in figure 1; transects $\mathrm{S} 1$ and R1, R2, R3 respectively), elevation of about $0.5-3 \mathrm{~m}$ above sea level, and the apparent dip of buried scarps (and overlying post-erosional deposits) suggest that the erosional features are due to extreme coastal events. Figure 4 shows the photographs of the trenches showing the heavy mineral concentration.

Optical ages on core samples (as shown in figure 2) are stratigraphically consistent. Optical ages of sans immediately overlying the imaged erosional scarp dates the events to transect S1: $340 \pm$ 35 (M10), $1175 \pm 188$ (M9), $2489 \pm 293$ (M8); transect R1: $490 \pm 30(\mathrm{M} 1), 880 \pm 40(\mathrm{M} 2), 1080 \pm$ 60 (M4); transect R2: $350 \pm 20$ (M7), $2450 \pm 130$ (M6), $3710 \pm 200$ (M5); transect R3: $2193 \pm 266$ (M13), $2235 \pm 881$ (M12), $2585 \pm 609$ (M11). The first scarp from the seashore corresponding to transect $\mathrm{S} 1$ is approximately $10 \mathrm{~m}$ from the shore suggesting a substantial erosional episode at of $340 \pm$ 35 years BP, and the two older scarps nearly $20 \mathrm{~m}$ 
from the shore and approximately $30 \mathrm{~m}$ from the shore, date back to $1175 \pm 188$ years and $2489 \pm$ 293 years respectively (figure 3 ). We speculate that the scarp ' $\mathrm{C}$ ' which yields an age of $340 \pm 35$ years may be similar to the most recent extreme wave events interpreted as tsunami deposits dated to $530 \pm 50$ cal years BP by Jankaew et al (2008). Second scarp from the seashore corresponding to transect S1 might represent the documented extreme wave event of $955 \pm 30$ cal years BP (Rajendran et al 2006) and speculates that the oldest dated scarp 'A' may correlate with the oldest sand sheet (2250 years old) of extreme wave events reported in Thailand by Jankaew et al (2008). The time interval of the events represented by buried scarps
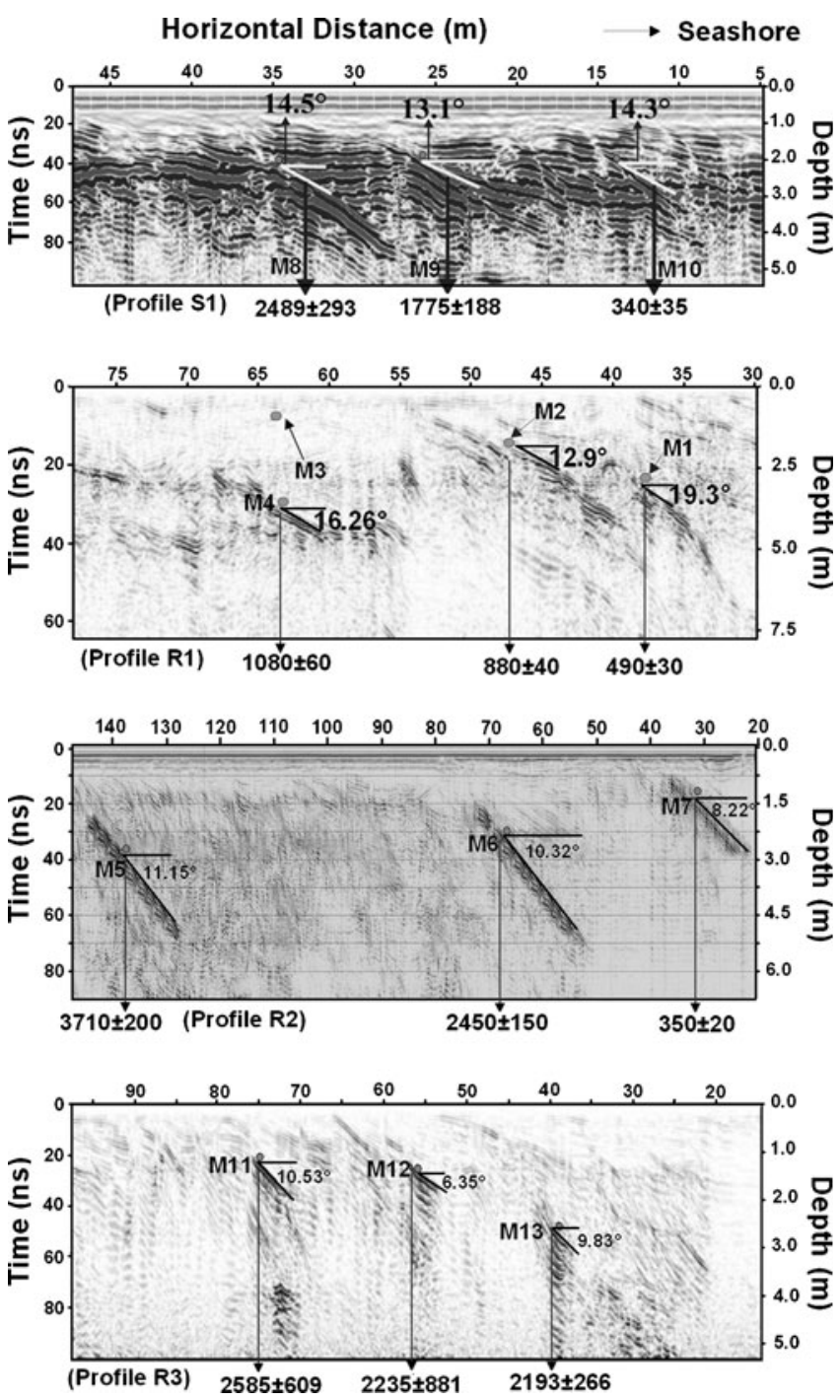

Figure 3. Shore-normal ground-penetrating radar (GPR) grey scale images for transect S1, R1, R2 and R3 highlighting prominent reflections in the upper part of the coastal plain sequence, which are interpreted as erosional disconformities. Images were collected with a Geophysical Survey Systems Inc. (GSSI) georadar system. OSL dates (yrs ago) obtained on sands immediately overlying each of the three buried scarps is also shown.
$\mathrm{C}-\mathrm{B}$ is $800-900$ years, whereas the gap between the older scarps is $1100-1300$ years. A high amplitude reflection in the GPR survey indicates zones of high dielectric constant. In our present case, it is due to the presence of heavy minerals in a steeply dipping signature. GPR data shows three characteristic events and not a single continuous scarp and these correlate well with three timings of these events. We also document the evidences of other scarp faces and further studies need to be carried out for regional correlation of these horizons along the northern margin of Indian Ocean.

A scarp is a steep erosional feature produced by natural processes (storm waves, tsunamis, flooding). In trenches, they will be steeply-dipping unconformities covered by new sediments. Commonly, heavy minerals (magnetite, ilmenite, garnet, hornblende, zircon, and tourmaline) concentrate while light minerals (quartz, feldspar) are washed away. Heavy minerals get accumulated as dipping reflectors due to high wave energy associated with tsunamis/storms resulting in well sorting of minerals and carrying high density minerals and depositing as a characteristic event as dipping reflectors. Whatever minerals are present in the sand, will be concentrated - there is no diagnostic assemblage for storms vs. tsunamis. One has to look at the context of HMCs, its dip, granularity and texture to figure that out.

The profile R2, which is adjacent to a surge channel of the 2004 Tsunami, shows a comparable sequence of buried scarps (figure 3 ). The distance of the GPR profile in this case is about $125 \mathrm{~m}$ from the present shoreline buried scarps occurred at 30 , 65 and $140 \mathrm{~m}$ from the shoreline with OSL ages of $350 \pm 20$ (scarp angle of $8.22^{\circ}$ ), $2450 \pm 130$ (scarp angle of $10.32^{\circ}$ ) and the oldest event $3710 \pm 200$ (scarp angle of $11.15^{\circ}$ ), respectively.

We hypothesize that our optical ages suggest a recurrence interval of 900-1200 years, with a high-frequency component of $\sim 300$ years. Textural characteristics of these deposits, confirm the fining upward sequence and a decrease in thickness in a landward direction. In addition to the geophysical records, substantial magnetite (density $=5.2$ ) fraction increases the possibility of an extreme wave event rather than eolian activity. Since fair-weather waves typically cannot concentrate such high density minerals as magnetite to any considerable thickness, we suggest the possibility of extreme wave reworking being responsible for the subsurface event horizons. However, we do not attribute these solely to tsunami origin (although tsunami vs. storm origin cannot be confirmed by subsurface records and sedimentological trends alone, comparisons with the 2004 event suggests that at least some of the event horizons may have been produced by tsunamis). Conversely, 


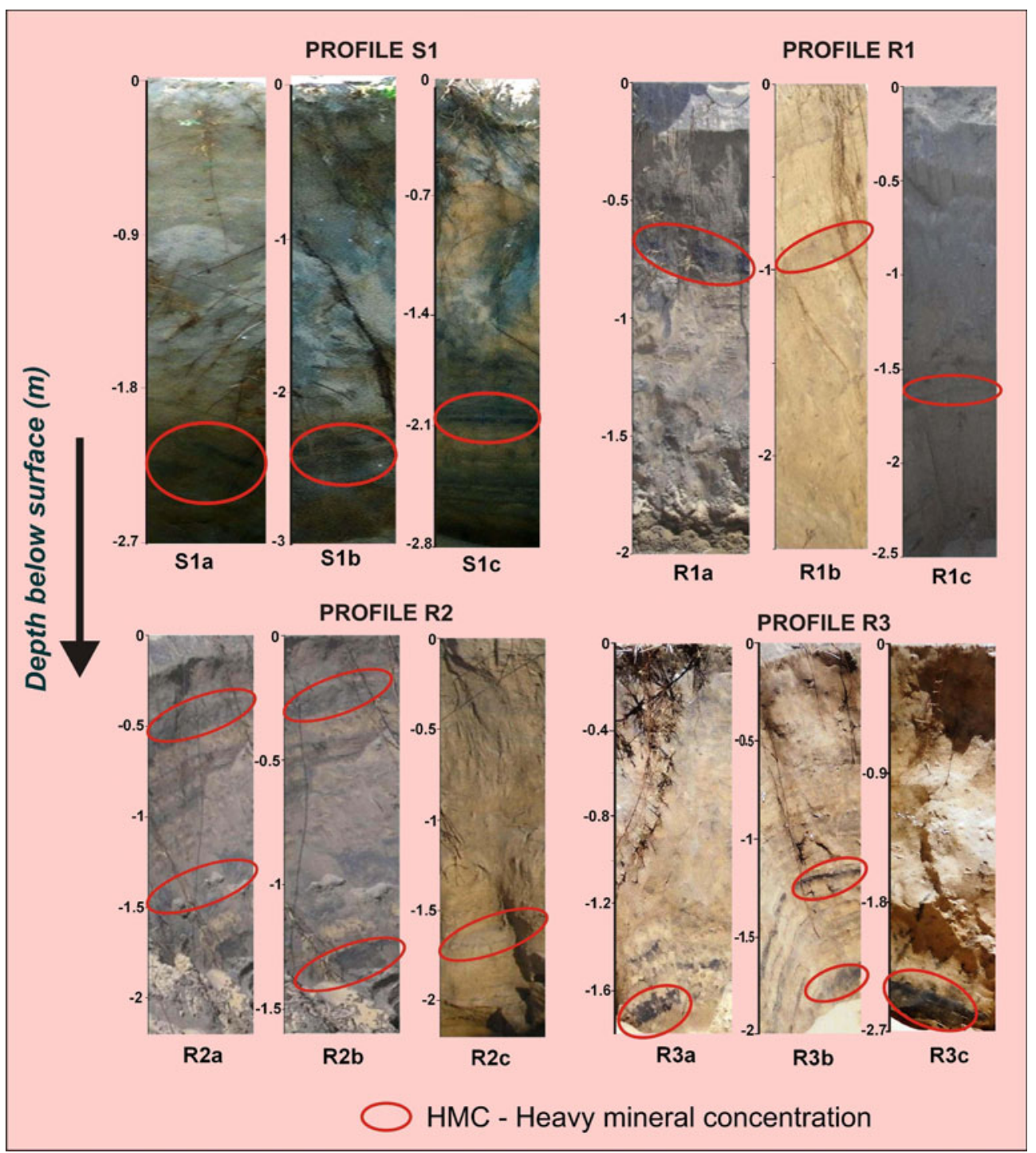

Figure 4. File photograph of trench exposures along all the four GPR transect (S1, R1, R2 and R3).

not all buried scarps along the west coast of US may have been tsunami-related (cf. Meyers et al 1996). In many instances, basin-wide studies can confirm that an event may be a large tsunami, rather than a regional storm that is not likely to affect the entire basin. Shore normal GPR profiles in beach ridges are the ideal ones to demarcate signatures of extreme wave events, as demonstrated by Buynevich et al (2007b), who used a single shore normal profile of length up to $100 \mathrm{~m}$ in demarcating the extreme wave events of North Atlantic, and our present approach matches with such methodologies and thus remain confident of the approach used for inference in our present study (Nair et al 2010). Our profiles S1, R1, R2 and R3 are therefore capable of capturing such signatures of extreme wave events.

In this study, buried scarps in the sediment structure (i.e., formerly geomorphologic markers) found by GPR are interpreted as former extreme wave event scars and dated by OSL. However, in all palaeo-extreme wave event studies and those from more recent strong events, trim lines are demonstrated as good markers, as well as the landward limit of thinning of fine sediments from tsunami inundation. As inundation normally ends with zero energy at a certain line it is difficult to accept that a scarp (even in sand) forms the inundation limit, because a scarp is a document for a higher energy with transforming forces on a given topography. The modern example from the 2004 event shows a side bank of a flow channel as equivalent and modern analogue, which is not a document for inundation in general. We hypothesize that while storms in GPR images will show us several dipping reflectors with presence of sedimentary structures; tsunami events may be marked by strong isolated dipping reflectors with high 
magnetite content, absence of sedimentary structures and control of sorting on granularity.

Although Shiki et al (2008) emphasized the fact that there is no single aspect to discriminate between storm and tsunami deposits, as they share most of the typical characteristics, we maintain that based on positive far-field correlations and our present observations that basal erosional unconformites and fining-up sequences (normal grading) serve as reliable signatures of fine-grained tsunami deposits (Nair et al 2010).

\section{Conclusions}

Our study demonstrates that the sand-rich coastal sequences along the eastern Indian coast provide ideal settings for reconstructing past erosional events. Our approach improves upon the previous records by (1) location and mapping of event signatures with georadar; (2) use of heavy minerals as indicators of extensive sediment reworking, and (3) employing in-situ OSL dates, which are superior to radiocarbon dating due to a paucity or lack of macrofossils, and inherent problems with reservoir effect in mollusks and their potential reworking from much older deposits. The combined geophysical, sedimentological, and geochronological dataset suggest that the relict scarps were produced by extreme wave events $\sim 300,1200$, and 2500 years ago. Only regional or basinscale studies on their chronology will help distinguish tsunami signatures from storm-generated features.

\section{Acknowledgements}

This project was funded by INCOIS, Ministry of Earth Science, India. Prof. Brain F Atwater provided insightful suggestions and several clarifications. We also thank the three anonymous reviewers and the Editor for their constructive suggestions that helped to improve the manuscript considerably. We would like to thank the students from IIT Kharagpur, Mardanya N, Maiti S and Ghosal $\mathrm{T}$ for their assistance in GPR data processing. We extend our thanks to the Archeological Survey of India, Chennai for the help in field investigations.

\section{References}

Aitken M J 1998 An introduction to optical dating: The dating of Quaternary sediments by the use of photonstimulated luminescence (USA, New York: Oxford University Press) 280p.
Babu N, Suresh Babu D S and Mohan Das P N 2007 Impact of tsunami on texture and mineralogy of a major placer deposits in southwest coast of India; Environ. Geol. 52 71-80.

Bailey R M et al 1997 Partial bleaching and the decay form characteristics of quartz OSL; Radiation Measurements 27(2) 123-136.

Bøtter-Jensen L et al 2003 Optically stimulated luminescence dosimetry, 1st edn (Amsterdam, Netherlands: Elsevier Science), 374p.

Buynevich I V, FitzGerald D M and van Heteren S 2004 Sedimentary records of intense storms in Holocene barrier sequences, Maine, USA; Mar. Geol. 210 135-148.

Buynevich I V, FitzGerald D M and Goble R J 2007a A 1500 yr record of North Atlantic storm activity based on optically dated relict beach scarps; Geology $\mathbf{3 5}$ $543-546$.

Buynevich I V, Bitinas A and Pupienis D 2007b Lithological anomalies in a relict coastal dune: Geophysical and paleoenvironmental markers; Geophys. Res. Lett. 34 L09707, doi: 10.1029/2007GL029767.

Buynevich I V, Jol H M and FitzGerald D M 2009 Coastal Environment; In: Ground Penetrating Radar: Theory and Applications (ed.) Jol H M, Elsevier, pp. 299-322.

Clarke M, Rendell H, Tastet J-P, Clave B and Masse L 2002 Late-Holocene sand invasion and North Atlantic storminess along the Aquitaine Coast, southwest France; The Holocene 12 231-238.

Jain M and Singhvi A K 2001 Limits to depletion of bluegreen light stimulated luminescence in feldspars: Implications for quartz dating; Radiation Measurements $33(6)$ $883-892$.

Jain M et al 2003 Characterisation of blue-light stimulated luminescence components in different quartz samples: Implications for dose measurement; Radiation Measurements 37(4-5) 441-449.

Jankaew K, Atwater B F, Sawai Y, Choowon M, Charoentitirat T, Martin M E and Prendergast A 2008 Medieval forewarning of the 2004 Indian Ocean tsunami in Thailand; Nature 455 1228-1231.

Jol H M, Smith D G and Meyers R A 1996 Digital ground penetrating radar (GPR): A new geophysical tool for coastal barrier research (examples from the Atlantic, Gulf and Pacific coasts, U.S.A.); J. Coast. Res. 12 960-968.

Meyers R, Smith D G, Jol H M and Peterson C D 1996 Evidence for eight great earthquake subsidence events detected with ground penetrating radar, Willapa barrier, Washington; Geology 24 99-102.

Monecke K, Finger W, Klarer D, Kongko W, McAdoo B G, Moore A L and Sudrajat S U 2008 A 1000-year sediment record of tsunami recurrence in northern Sumatra; Nature 455 1232-1234.

Morton R A, Gelfenbaum G and Jaffe B E 2007 Physical criteria for distinguishing sandy tsunami and storm deposits using modern examples; Sedim. Geol. 200 184-207.

Murari M K 2008 Component specific luminescence of natural minerals and their application to the dosimetry of natural radiation environment; Mohanlal Sukhadia University, Udaipur, 141p.

Murari M K and Singhvi A K 2006 Component specific paleodose estimation in optically stimulated luminescence dating: Methodology, applications and implications (Oral Presentation), paper presented at Asia-Pacific Conference on Luminescence Dating (APLD), Hongkong, China.

Murari M K, Achyuthan H and Singhvi A K 2007 Luminescence studies on the sediments laid down by the December 2004 tsunami event: Prospects for the dating 
of palaeo tsunamis and for the estimation of sediment fluxes; Curr. Sci. 92 367-371.

Murray A S and Olley J M 2002 Precision and accuracy in the optically stimulated luminescence dating of sedimentary quartz: A status review; Geochronometria 21 11-16.

Murthy K S R, Subrahmanyam A S, Lakshmi Narayana S, Chandrasekar D V and Rao T C S 1995 Some geodynamic aspects of the Krishna-Godavari basin, east coast of India; Cont. Shelf Res. 15 779-788.

Nagendra R, Kamalakannan B V, Sajith C, Sen G, Reddy A N and Srinivasulu S 2005 A record of foraminiferal assemblage in tsunami sediments along Nagapattinam coast, Tamil Nadu; Curr. Sci. 89 19471952.

Nair R R, Buynevich I, Goble R J, Srinivasan P, Murthy S G N, Kandpal S C, Vijayalakshmi C S and Trivedi D 2010 Subsurface images shed light on past tsunamis in India; Eos, Transactions American Geophysical Union 91(50) 489-490.

Rajendran C P, Rajendran K, Machado T, Satyamurthy T, Aravazhi P and Jaiswal M 2006 Evidence of ancient sea surges at the Mamallapuram coast of India and implications for previous Indian Ocean tsunami events; Curr. Sci. 91 1242-1247.

Ramaiyan M, Krishna Prasad E and Suresh P K 1997 Shoreline oscillation of Tamil Nadu coast; In: Proc. Second Indian National Conference of Harbour and Ocean Engineering, Trivandrum, pp. 1176-1181.

Selvaraj K and Ram Mohan V 2003 Textural variation and depositional environments of innershelf sediments off
Kalpakkam, southeast coast of India; J. Geol. Soc. India 61 449-462.

Shiki T, Tsuji Y, Yamazaki T and Minoura K 2008 Tsunamiites Features and Implications, Elsevier, pp. 1-2.

Singhvi A K and Porat N 2008 Impact of luminescence dating on geomorphological and palaeoclimate research in drylands; Boreas 37 536-558.

Singhvi A K et al 2008 Sensitivity changes during OSL read out: Implications and modified SAR protocol, paper presented at ICLA 2008, NPL, New Delhi.

Sommerville A A, Hansom J D, Sanderson D C W and Housley R A 2003 Optically stimulated luminescence dating of large storm events in Northern Scotland; Quat. Sci. Rev. 22 1085-1092.

Srinivasulu S, Thangadurai N, Switzer A D, Ram Mohan $\mathrm{V}$ and Ayyamperumal T 2007 Erosion and sedimentation in Kalpakkam (N Tamil Nadu, India) from the 26th December 2004 tsunami; Mar. Geol. 240 65-75.

Subrahmanyan K S and Selvan T A 2001 Geology of Tamil Nadu and Pondicherry; Geol. Soc. India Spec. Publ. p. 192.

Vijayalakshmi C S, Srinivasan P, Murthy S G N, Trivedi D and Nair R R 2010 Granularity and textural analysis as a proxy for extreme wave events; J. Earth. Syst. Sci. 119(3) 297-305.

Wintle A G and Murray A S 2006 A review of quartz optically stimulated luminescence characteristics and their relevance in single-aliquot regeneration dating protocols; Radiat. Meas. 41 369-391.

Wintle A G 2008 Luminescence dating of Quaternary sediments - Introduction; Boreas 37 469-470. 